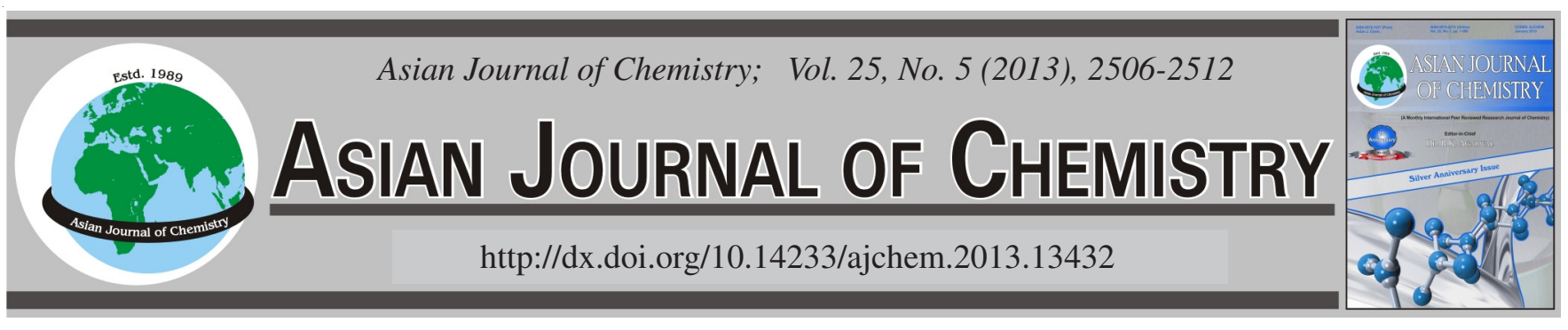

\title{
Selective Spectrophotometric Determination of Aluminium with Xylenol Orange in Acidic Media Using Partial Least Square Method
}

\author{
Mohammad Saber Tehrani ${ }^{1, *}$, Jahan B. Ghasemi $^{2}$ and Mohammad Taghi Baharifard ${ }^{1}$
}

${ }^{1}$ Department of Chemistry, Science and Research Branch, Islamic Azad University, Tehran, Iran

${ }^{2}$ Department of Chemistry, Faculty of Science, K.N. Toosi University of Technology, Tehran, Iran

*Corresponding author: Fax: +98 21 44869761-2; Tel: +98 21 44869761; E-mail: msabertehrani1 @ gmail.com

(Received: 12 January 2012;

Accepted: 9 November 2012)

AJC-12390

\begin{abstract}
A simple selective and efficient analytical method for the determination of aluminium in water and real samples is proposed. The procedure is based on the reaction of aluminium ion with xylenol orange in acidic media prior to its spectrophotometric determination using partial least squares (PLS) method. A set of 20 calibration samples was employed to build the model At the best modeling conditions, the SEC were 0.0256 and 0.0148 and the REP were 4.45 and $2.58 \%$ for calibration and prediction set, respectively. The mean recoveries and relative standard deviations (RSD) for aluminium prediction by PLS-1 were found to be $100.58 \pm 2.99(\mathrm{n}=6)$. Finally, quantitative determination of aluminium in natural water samples and aluminium gel tablets and bauxite and bentonit samples were examined for aluminium content successfully by the proposed method.
\end{abstract}

Key Words: Spectrophotometric determination, Multivariate calibration, Aluminium, Partial least square, Xylenol orange, Real water, Aluminium gel tablet, Bauxite, Bentonit.

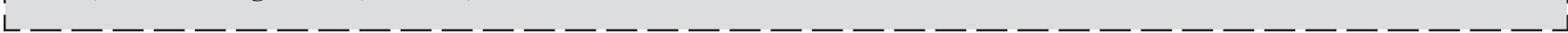

\section{INTRODUCTION}

The toxicity of aluminium as well as the need for sensitive and selective methods for determining this element in natural waters, plant digests, soil extracts and many other samples is currently attracting. Instrumental techniques such as AAS and ICP are the main methods using for metal determination in many laboratories. Determination of aluminium in the sample solutions that frequently contain low level of aluminium content, the precision of flame atomic absorption spectrometry is poor and the high dissolved-solids content of many of the soil extractants can cause severe clogging of the burner slot. A spectrophotometric technique is always an acceptable alternative chemical analysis method, due to its acceptable precision and accuracy, associated with its lower cost compared to other techniques. In fact, interest in UV-VIS spectrophotometric methods has increased and been renewed through the use of signal processing and multivariate techniques such as partial least squares (PLS) regression and artificial neural networks. These tools can allow simultaneous spectrophotometric determination of several elements as well as improve the data handling process of complex chemical systems. There is some reagents for spectrophotometric determination of Al, including aluminun, hematoxylin, pontachrome blue black R, oxine, eriochrome cyanine $\mathrm{R}$, quinalizarin, alizarin $\mathrm{S}$, arsenazo, cupferron, stilbazo, morin and xylenol orange (XO). Of these reagents xylenol orange performs a highly sensitive colour with Al even in acidic solution ${ }^{1}$. Xylenol orange [3,3-bis-N,Ndi(carboxymethyl)-aminomethyl-o-cresol sulphonphetalein] (XO) is an excellent complexometric indicator for determination of many metal ions ${ }^{2}$. Fig. 1. shows The chemical structure of xylenol orange. Xylenol orange has been recommended for high sensitivity spectrophotometric determination of aluminium.<smiles>Cc1cc(C2(c3cc(C)c(O)c(CN(CC(=O)[O-])CC(=O)[O-])c3)OS(=O)(=O)c3ccccc32)cc(CN(CC(=O)[O-])CC(=O)[O-])c1O</smiles>

Fig. 1. Chemical structure of xylenol orange

The reagent is not specific and many elements may cause interferences. In most cases the interference can be eliminated 
by $\mathrm{pH}$ control, masking or extraction. In aqueous solutions xylenol orange reacts slowly with aluminium at room temperature which necessitates a heating step in the colour development. Addition of the reagent in alcoholic solution greatly increases the rate of reaction ${ }^{3}$. Protonation and complex formation of xylenol orange with alkaline earth and aluminium ions has been studied ${ }^{2}$. Simultaneous determination of aluminium and beryllium in geological samples with xylenol orange in pH 5.6 also reported ${ }^{4}$. Selectivity can be improved by $\mathrm{pH}$ control or by masking metal cations with some complexing agent such as EDTA ${ }^{5,6}$.

Otomo ${ }^{1}$ has been used this reagent for determining $\mathrm{Al}$ in acidic media (acetate buffer) using univariate calibration technique. The present paper describes a spectrophotometric method for determination of aluminium, based on the highly sensitive colour reaction of xylenol orange with $\mathrm{Al}$ in potassium hydrogen phetalate (KHP) buffer solution by partial least square (PLS) method. The PLS-1 was written in MATLAB and used to determine the concentration of aluminium in synthetic and real samples according to algorithms described in references ${ }^{7}$.

Theory: Calibration is nowadays one of the most important fields of chemometrics and spectral data are perhaps the most common type of data to which chemometrics techniques are applied. The most traditional, but still widely used method of calibration in chemistry is univariate, involving calibrating a single variable (e.g., a spectroscopic intensity) to another variable (e.g., a concentration). The aim of calibration is to use information from the 'x' (or measurement) block (e.g., spectra, chromatograms, electrochemical measurements, molecular descriptors) to predict parameters in the 'c' block. In univariate calibration, both blocks consist of a single variable ${ }^{8}$. It is often advantageous to combine information from several or even all the spectral variables (multivariate technique) for calibration and concentration prediction of a species. Multivariate calibration is the collective term used for the development of a quantitative model for the reliable prediction of properties of interest $\left(\mathrm{y}_{1}, \mathrm{y}_{2}, \ldots, \mathrm{y}_{\mathrm{q}}\right)$ from a number of predictor variables $\left(\mathrm{x}_{1}, \mathrm{x}_{2} \ldots\right.$, $\mathrm{x}_{\mathrm{p}}$ ). As an example, one may think of the spectroscopic analysis of a mixture in order to measure the concentration of one or more of its constituents. Multivariate calibration is set apart from univariate calibration because it involves more than one predictor variable using the entire spectral information may, in principle, lead to better predictions. However, it also opens the possibility that essentially non-informative spectral regions are included in the model through chance correlations in the calibration set. Having more than one predictor admits the estimation of more than one dependent property and correction for undesired covariates (interferences). In fact, the latter prospect is a major motivation for doing the multivariate measurements. In univariate calibration it is not possible to correct for interferences without additional information. With additional information, i.e., with multivariate data, the opportunity arises to separate the information relevant for the respective properties from non-relevant variation or random noise ${ }^{9}$. In brief multivariate calibration offer several advantage over univariate approaches ${ }^{4}$. It is possible to analyze for multiple components simultaneously. Multiple redundant measurements can also provide improved precision in prediction, due to the fact that $\mathrm{n}$ measurement and calculating mean value will result in a factor of $V_{\mathrm{n}}$ reduction in the standard deviation of the mean (signal averaging). Redundant measurements in multivariate calibration also facilitate fault detection and presence of interferent. Multivariate calibration can lead to paradigm shift in problem solving using overlapped bands for quantitative analysis (e.g., the prediction of protein content in wheat).

Beer's law for single component systems using multivariate calibration: Beer's law model for $m$ calibration standards containing 1 chemical Component with spectra of $n$ digitized absorbances can be presented in matrix notation as:

$$
\mathrm{A}=\mathrm{CK}+\mathrm{E}
$$

or in matrix form,

$$
\begin{aligned}
& {\left[\begin{array}{cccc}
\mathrm{A}_{11} & \mathrm{~A}_{12} & \ldots & \mathrm{A}_{1 \mathrm{n}} \\
\cdot & \cdot & \ldots & \cdot \\
\mathrm{A}_{\mathrm{m} 1} & \mathrm{~A}_{\mathrm{m} 2} & \ldots & \mathrm{A}_{\mathrm{mn}}
\end{array}\right]} \\
& =\left[\begin{array}{c}
\mathrm{C}_{11} \\
\vdots \\
\mathrm{C}_{\mathrm{m} 1}
\end{array}\right]\left[\begin{array}{llll}
\mathrm{K}_{11} & \mathrm{~K}_{12} & \cdots & \mathrm{K}_{1 \mathrm{n}}
\end{array}\right]+\left[\begin{array}{cccc}
\mathrm{E}_{11} & \mathrm{E}_{12} & \cdots & \mathrm{E}_{1 \mathrm{n}} \\
\vdots & \vdots & \cdots & \vdots \\
\mathrm{E}_{\mathrm{m} 1} & \mathrm{E}_{\mathrm{m} 2} & \cdots & \mathrm{E}_{\mathrm{mn}}
\end{array}\right]
\end{aligned}
$$

where $\mathrm{A}$ is the $\mathrm{m} \times \mathrm{n}$ absorption matrix of calibration spectra, $\mathrm{C}$ is the $\mathrm{m} \times 1$.

Concentration matrix of component (Al-xylenol orange complex) concentrations, $\mathrm{K}$ is the $1 \times \mathrm{n}$ matrix of absorptivity constants or simply the calibration matrix. $\mathrm{E}$ is the $\mathrm{m} \times \mathrm{n}$ matrix of spectral errors that not fit by the model. The elements of $\mathrm{K}$ matrix can be determined by measuring spectra of component in calibration samples. In literature, there are many chemometric techniques that effectively solved eqn. 2 and found the perfect relation between the absorbance and concentration. Among these calibration methods, the most employed methods are classical least squares (CLS), principal component regression (PCR), partial least squares (PLS). Owing to the development of new instrumentation, data sets in which object is described by several hundreds of variables can be easily obtained. Partial least squares can easily treat these large data matrices, extracting the relevant part of the information and producing reliable but very complex models ${ }^{10}$.

The partial least squares is a quantitative spectral decomposition technique that is closely related to principal component regression (PCR). However, in PLS the decomposition is performed in a slightly different fashion. Instead of firstly decomposing the spectral matrix into a set of eigenvectors and scores and regressing them against the concentrations as a separate step, PLS actually uses the concentration information during the decomposition process. This causes spectra containing higher constituent concentrations to be weighted more heavily than those with low concentrations. Thus, the eigenvectors and scores calculated using PLS is quite different from those of PCR. The main idea of PLS is to get as much concentration information as possible into the first few loading vectors. There are actually two versions of PLS algorithm; PLS-1 and PLS-2. The differences between these methods are subtle but have very important effects on the results. In PLS1 , a separate set of scores and loading vectors is calculated for each constituent of interest. In this case, the separate set of 
scores and loading vectors are specifically tuned for each constituent and therefore, should give more accurate predictions than PCR or PLS-2.

PLS-1 calibration method: Usually, multivariate calibration methods involve a calibration step in which the relationship between spectra and components concentrations is estimated from a set of calibration samples and a prediction step in which the results of the calibration are used to predict the components concentrations in an unknown sample spectrum $^{11}$.

Partial least squares type 1 (PLS-1) is a factor analysis method which has full spectrum advantages of its classical counterpart (CLS). The method keeps the advantages of inverse calibration, allowing us to carry out the analysis for one chemical component at a time. In the PLS-1 type, all parameters are optimized for the determination of a single analyte of interest. In PLS-1, the calibration spectra can be represented as:

$$
\mathrm{A}=\mathrm{TP}^{\mathrm{t}}+\mathrm{E}_{\mathrm{R}}
$$

where $\mathrm{A}$ is an $\mathrm{m} \times \mathrm{n}$ matrix containing the spectra of $\mathrm{m}$ calibration samples obtained at $n$ wavelengths, $P$ is a $n \times h$ matrix containing the full spectrum vectors (loadings), $\mathrm{T}$ is an $\mathrm{m} \times \mathrm{h}$ matrix of intensities (or scores) in the new coordinate system defined by the $h$ loading vectors and $E_{R}$ is the $m \times n$ matrix of spectral residuals not fitted by the optimal PLS- 1 model. The loading vectors contained in $\mathrm{P}$ are usually determined by an iterative algorithm, which also provides a set of orthogonal weight loading factors that form the $n \times h$ matrix $W$. The mutual relationship between $\mathrm{A}, \mathrm{P}, \mathrm{T}$ and $\mathrm{W}$ is expressed in the following equation

$$
\mathrm{T}=\mathrm{RW}\left(\mathrm{P}^{\mathrm{t}} \mathrm{W}\right)^{-1}
$$

In PLS-1, the matrix $\mathrm{T}$ is related to concentration by an inverse regression step as shown in eqn. 5:

$$
\mathrm{C}_{\mathrm{k}}=\mathrm{TV}+\mathrm{E}_{\mathrm{c}}
$$

where $C_{k}$ is the $m \times 1$ vector of the concentrations of analyte $k$ in the calibration samples, $V$ is the $h \times 1$ vector of coefficients relating the scores to the concentrations and $E_{c}$ collects the corresponding concentration residuals. In the prediction step, the spectrum $r$ registered for an unknown sample is transformed into the sample score tr by:

$$
\mathrm{t}_{\mathrm{r}}\left(\mathrm{W}^{\mathrm{t}} \mathrm{P}\right)^{-1} \mathrm{~W}^{\mathrm{T}} \mathrm{r}
$$

From which the concentration can be calculated as:

$$
\mathrm{C}_{\mathrm{K}, \text { un }}=\mathrm{t}_{\mathrm{r}}{ }^{\mathrm{t}} \mathrm{V}
$$

where $\mathrm{V}$ is the vector of regression of eqn. 5 .

\section{EXPERIMENTAL}

All the chemicals used of analytical reagent grade and deionized water was used throughout. Stock solutions of Al(III) and other metallic ions were prepared from their commercial nitrate salts and standardized titrimetrically with EDTA in the presence of suitable indicator. The EDTA standardized titrimetrically against solution which prepared from vacuum dried calcium carbonate. Stock solutions of diverse elements were prepared from the high purity salts of the cations (all from Merck, Germany). A stock xylenol orange $\left(7.89 \times 10^{-5}\right.$
M ) solution was prepared by dissolving appropriate amount of reagent in a beacher in some hot water and after dissolution diluted to the mark with Double-distilled water in a volumetric flask. Working solutions were made by appropriate dilution. Buffer solution of $0.05 \mathrm{M}$ ( $\mathrm{pH}$ 3.0) was prepared by dissolving $5.1 \mathrm{~g}$ of analytical grade potassium hydrogen phetalete (KHP) in nearly $400 \mathrm{~mL}$ doubly distilled water and adding concentrated $\mathrm{HCl}$ to adjust $\mathrm{pH}$ to 3 in the presence of $\mathrm{pH}$ electrode and then dilute to mark $(500 \mathrm{~mL})$ in a volumetric flask.

Atomic absorption measurements were performed by using a Varian AA240 apparatus with flame (air-acetylene) atomization and deuterium background correction. The instrumental settings of the manufacturers were followed. Absorption measurements were carried out on a Carry 100 spectrophotometer (slit width: $0.2 \mathrm{~nm}$, scan rate: $500 \mathrm{~nm} / \mathrm{min}$ ) using 1.00 $\mathrm{cm}$ quartz cells. All absorbance spectra were digitized and stored at wavelengths from 350-700 nm in steps of $1 \mathrm{~nm}$ and then transferred in ASCII format to a Pentium IV (2 Gb RAM) computer for subsequent manipulation by PLS program. Measurements of $\mathrm{pH}$ were made with a Metrohm $827 \mathrm{pH}$ meter using a combined electrode. The data pretreatment was done with MATLAB for windows (Mathworks, Version 7.6). PLS program for calibration-prediction and experimental design was written in MATLAB according to the algorithm described by Martens and Naes and PLS routine of PLS Toolbox (Eigenvector Company, Version 7.6). The Savitzky- Golay, 11 points filter is used for smoothing absorption spectra.

Spectrophotometric determination of Al: An aliquot of $\mathrm{Al}$ was taken in a $25-\mathrm{mL}$ volumetric flask with a tightly fitting stopper. Then, appropriate volume of (xylenol orange) in each case was added to the solution and the mixture was diluted to $25 \mathrm{~mL}$ with $0.05 \mathrm{M}$ KHP buffer solution (pH 3.0) after Heating the volumetric flasks in $70{ }^{\circ} \mathrm{C}$ for $8 \mathrm{~min}$ in water bath and cooling to room temperature, the absorption spectra were recorded at 350-700 nm versus water as a blank. A similar procedure was used for the mixture of $\mathrm{Al}$ with diverse cations.

Procedure for calibration: In this method, a set of 20 solutions for Al between $0.0432-0.864 \mathrm{mg} / \mathrm{L}$ was made, from the working solution as follows. The desired amount of the standard solution of $\mathrm{Al}$ was placed in a $25-\mathrm{mL}$ volumetric flask and $1.5 \mathrm{~mL}$ xylenol orange solution $\left(1.58 \times 10^{-3} \mathrm{M}\right)$ was added to it and then diluted to the final volume with KHP buffer solution ( $\mathrm{pH}$ 3.0). The binary mixture solution of $\mathrm{Al}$ and diverse cations also, prepared as mentioned above.

\section{RESULTS AND DISCUSSION}

Optimization of experimental conditions affecting complex formation: Many experimental conditions may affect the absorption characteristics of Al-xylenol orange complex. Among these, $\mathrm{pH}$ and ionic strength of solution and heating time are the most important. The spectra of $\mathrm{Al}$ complex with xylenol orange was recorded against a blank (Fig. 2). The complex of Al-xylenol orange, exhibited absorption maximum at 550.

Effect of pH: The influence of $\mathrm{pH}$ on Al-xylenol orange absorption intensity was studied over a wide $\mathrm{pH}$ range (2-10.5). A reagent concentration of $1.93 \times 10^{-5} \mathrm{M}$ and $\mathrm{Al}$ concentration of $7.88 \times 10^{-5}$ was chosen. The results obtained were presented in Fig. 3. 


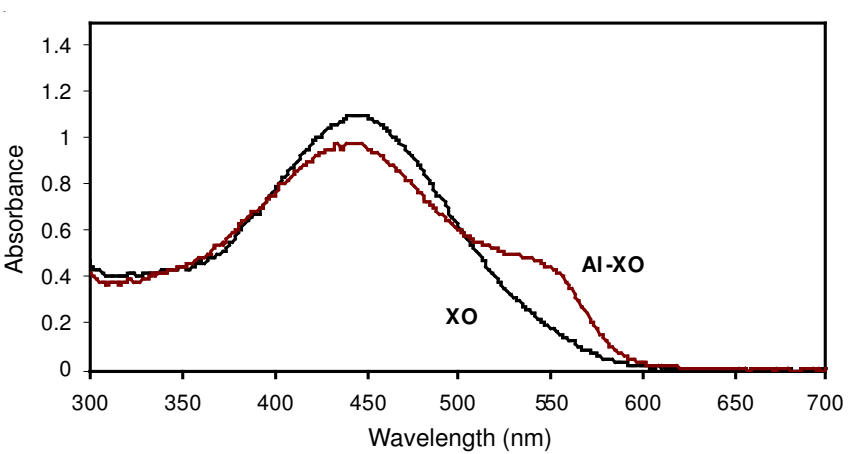

Fig. 2. Absorption spectra of xylenol orange and Al-xylenol orange $\mathrm{C}_{\mathrm{Al}}=$ $3.2 \times 10^{-5} \mathrm{C}_{\mathrm{Xo}}=6.31 \times 10^{-5}\left(\mathrm{C}_{\mathrm{M}} / \mathrm{C}_{\mathrm{L}}=0.5\right), \mathrm{pH}=3$

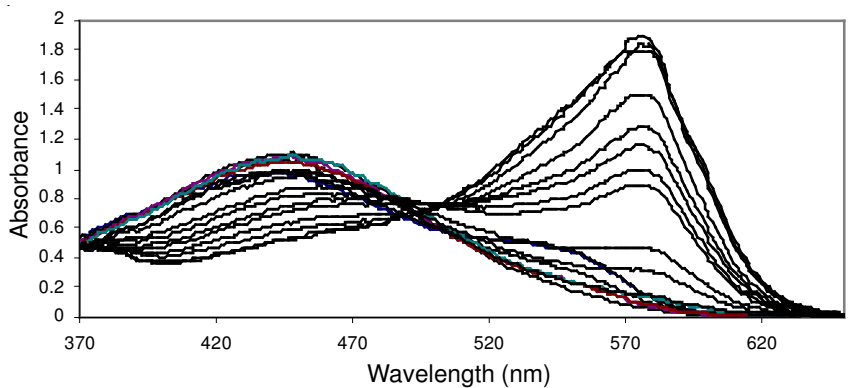

Fig. 3. Effect of the $\mathrm{pH}$ of the medium on the absorption spectra of Alxylenol orange complex

Fig. 4 shows the plot of absorbance-pH data for the Alxylenol orange system and the trend of variation in absorbance value at $\lambda_{\max }$ of complex $(550 \mathrm{~nm})$.

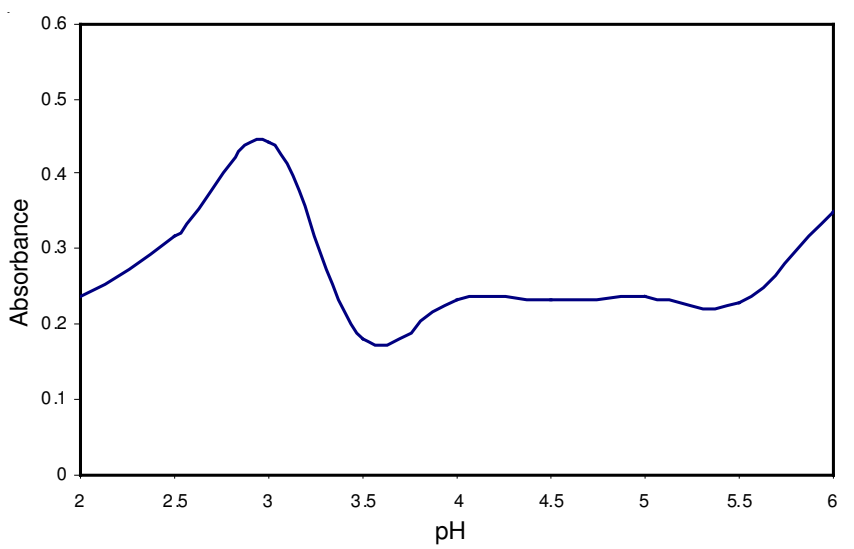

Fig. 4. Influence of $\mathrm{pH}$ on the absorption of Al-xylenol orange at $(550 \mathrm{~nm})$

Figs. 3 and 4 show that the best $\mathrm{pH}$ in acidic region for detecting and determining the aluminium complex is $\mathrm{pH}=3$. in this $\mathrm{pH}$ many interfering cations do not form any complexes with xylenol orange. So this $\mathrm{pH}$ can probably be a good $\mathrm{pH}$ for selective determination of $\mathrm{Al}$ in presence of many other cation. Hence, the absorption spectra for Al-xylenol orange were recorded at $\mathrm{pH}=3$.

Effect of heating: As in the case of the titration of aluminium with EDTA, the colour reaction of xylenol orange with aluminium is slow at room temperature, $c a$. $4 \mathrm{~h}$ were required for complete colour development ${ }^{1}$. When the solution containing xylenol orange and aluminium ions was heated on a boiling bath, however the reaction was greatly accelerated and the maximum colour development was obtained. For optimizing the heating time needed for complex formation completeness, similar solution of Al-xylenol orange complex were put in boiling bath water $\left(70^{\circ} \mathrm{C}\right)$ for different time and then its spectra was recorded (Fig. 5). As is shown in Fig. 5, the maximum colour development was reached after about 8 min in $70{ }^{\circ} \mathrm{C}$ so for all of complex solution at least $8 \mathrm{~min}$ heating was performed before recording of spectra.

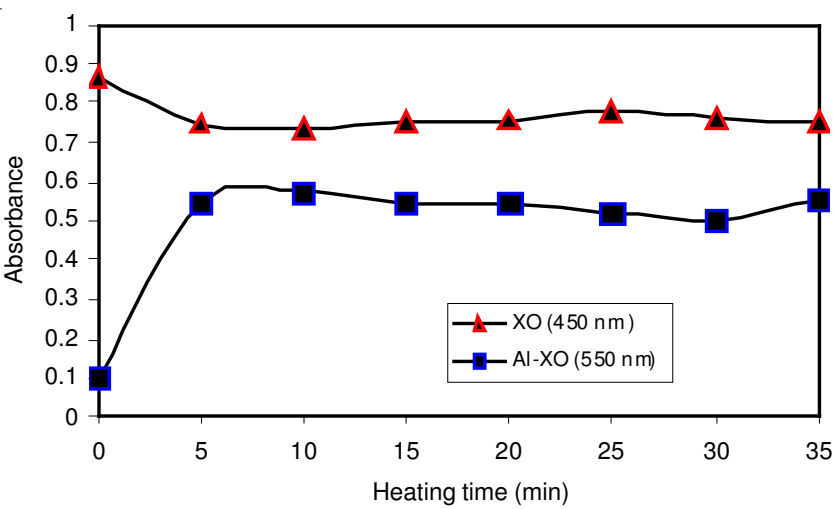

Fig. 5. Effect of heating time on colour development for Al-xylenol orange complex $\mathrm{C}_{\mathrm{Al}}=3.2 \times 10^{-5} \mathrm{C}_{\mathrm{Xo}}=6.31 \times 10^{-5}$

Composition of complex: The composition of the Alxylenol orange complex was determined by the mole ratio method. the results are presented graphically in Fig. 6 from which it is evident that only one Al-xylenol orange complex with $\mathrm{M} / \mathrm{L}=0.5$ is present in $\mathrm{pH}=3$.

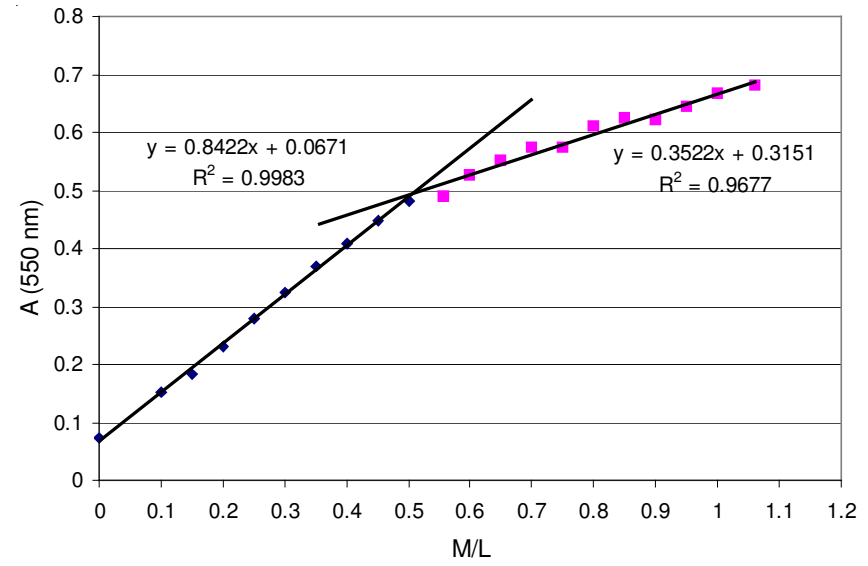

Fig. 6. Mole ratio plot for Al-xylenol orange complex

Univariate calibration: The linear working concentration range of Al xylenol orange was determined. These concentration ranges were useful in building both calibration and prediction sets. The linear concentration range of complex was determined by regressing absorbance at the corresponding $\lambda_{\max }(550$ $\mathrm{nm}$ )against concentration. The parameters of linear regression are given in Table-1. Linearity was observed between 0.0432 and $0.864 \mathrm{mg} \mathrm{L}^{-1}$ for aluminium.

TABLE-1

ANALYTICAL CHARACTERISTICS FOR SINGLE-COMPONENT DETERMINATION OF ALUMINIUM-XYLENOLORANGE (XO) AT ITS CORRESPONDING VISIBLE $\lambda_{\text {max }}$

$\begin{array}{ccccc}\mathrm{Al}-\mathrm{XO} & \lambda_{\max }(\mathrm{nm}) & \text { Slope } & \mathrm{r}^{2} & \text { Linear range }\left(\mathrm{mg} \mathrm{L}^{-1}\right) \\ - & 550 & 0.4875 & 0.9787 & 0.0432-0.8640\end{array}$


Preparation of calibration and prediction sets: In any chemometric study, two sets (or more) of solutions are prepared i.e., the calibration set and prediction (or validation) set. Calibration set is used to build the model, while the effectiveness of the proposed model for prediction is testified in the validation set. Typical one-compound calibration experiments (univariate calibration) were carried out to establish the concentration ranges for the determination in the mixture.

Twenty seven sample solutions (at $\mathrm{pH} 3.0$ ) of Al-xylenol orange were prepared. From these solutions, 21 solutions were selected as the calibration set and the remaining 6 solutions were kept as validation set. The compositions of calibration and prediction sets are presented in Table-2. The prediction set was selected randomly. For best calibration results, the spectral region within the range $(510-589 \mathrm{~nm})$ was chosen. The number of experimental points $(\lambda)$ per spectrum is 80 where the spectrum is subdivided into $1.0 \mathrm{~nm}$ intervals. Within this spectral region, maximum spectral information was available. Accordingly, the dimension of calibration absorption matrix (A) is $21 \times 80$, while the dimension for calibration concentration matrix $(\mathrm{C})$ is $21 \times 1$. It is advisable that the concentration ranges of $\mathrm{Al}$-xylenol orange in the prediction samples should cover the same space as that in calibration mixtures. The calibration set was selected over the concentration rang of $0.0432-0.864 \mathrm{mg} / \mathrm{L}$ of $\mathrm{Al}$, according to Table-2.

\begin{tabular}{cccc}
\multicolumn{5}{c}{ TABLE-2 } \\
COMPOSITION OF CALIBRATION AND PREDICTION \\
SETS USED FOR BUILDING AND TESTING THE PLS-1 \\
\multicolumn{4}{c}{ FOR DETERMINATION OF ALUMINIUM } \\
\hline No. & Al conc. (ppm) & No. & Al conc. (ppm) \\
\hline \multicolumn{4}{c}{ Calibration set } \\
\hline 1 & 0 & 11 & 0.432 \\
2 & 0.0432 & 12 & 0.4752 \\
3 & 0.0864 & 13 & 0.5184 \\
4 & 0.1296 & 14 & 0.5616 \\
5 & 0.1728 & 15 & 0.6048 \\
6 & 0.216 & 16 & 0.648 \\
7 & 0.2592 & 17 & 0.6912 \\
8 & 0.3024 & 18 & 0.7344 \\
9 & 0.3456 & 19 & 0.7776 \\
10 & 0.3888 & 20 & 0.8208 \\
- & - & 21 & 0.864 \\
\hline \multicolumn{5}{c}{ Prediction set } \\
\hline 21 & 0.1512 & 24 & 0.540 \\
22 & 0.2808 & 25 & 0.6696 \\
23 & 0.4104 & 26 & 0.7992 \\
\hline \multicolumn{4}{c}{}
\end{tabular}

Fig. 7 shows spectra of calibration set and Fig. 8 shows prediction of calibration concentration versus actual concentration.

Effective calibration by PLS-1 and selection of the optimum number of factors (h): The optimum number of factors (h) to be used within the PLS-1 algorithm is an important parameter to achieve better performance in prediction. This allows modeling of the system with the optimum amount of information, avoiding overfitting. To avoid overfitting, leaveone-out cross validation procedure was adopted. Simply, for $\mathrm{m}$ calibration set (21 solutions), the models were performed on $\mathrm{m} \times 1$ calibration solutions and use this calibration to predict the concentration in the sample left out. This process was repeated 21 times until each sample has been left out once ${ }^{11,12}$.

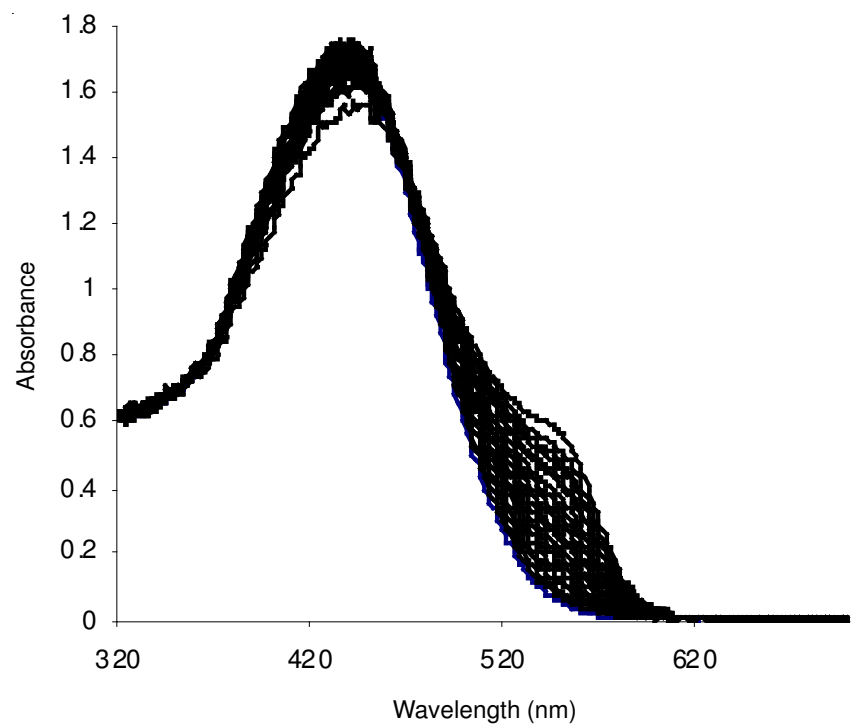

Fig. 7. Profiles of the spectra of calibration set of Al-xylenol orange used for the PLS1 calibration

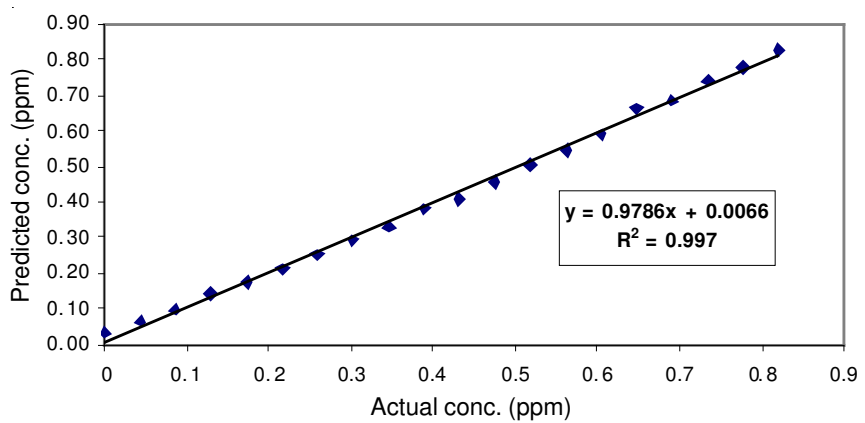

Fig. 8. Actual concentration versus predicted concentration for calibration set

The predicted concentration for each sample is then compared with the true concentration of this reference sample. PRESS (prediction error sum of squares), which measures the difference between predicted concentration and true one, is then estimated for all calibration samples in the set. PRESS value is also calculated after each increment in $\mathrm{h}$ as follows ${ }^{12}$.

$$
\text { PRESS }=\sum_{i=1}^{m}\left(C_{i, \text { pred }}-C_{i, \text { act }}\right)^{2}
$$

where $\mathrm{m}, \mathrm{C}_{\text {pred }}$ and $\mathrm{C}_{\mathrm{act}}$ are the total number of calibration samples, predicted concentration and the actual concentration of the Al, respectively.

Fig. 9 depicted the relation between PRESS values with the number of factors obtained from PLS-1 calibration.

The overall effectiveness of PLS-1 for prediction of Al-xylenol orange in the validation set can be determined by calculating REP (relative error of prediction) values for each analyte as follows ${ }^{12}$.

$$
\operatorname{REP}(\%)=100 \times\left[\frac{\sum_{i=1}^{n}\left(C_{i, \text { pred }}-C_{i, a c t}\right)^{2}}{\sum\left(C_{i, a c t}\right)^{2}}\right]^{1 / 2}
$$




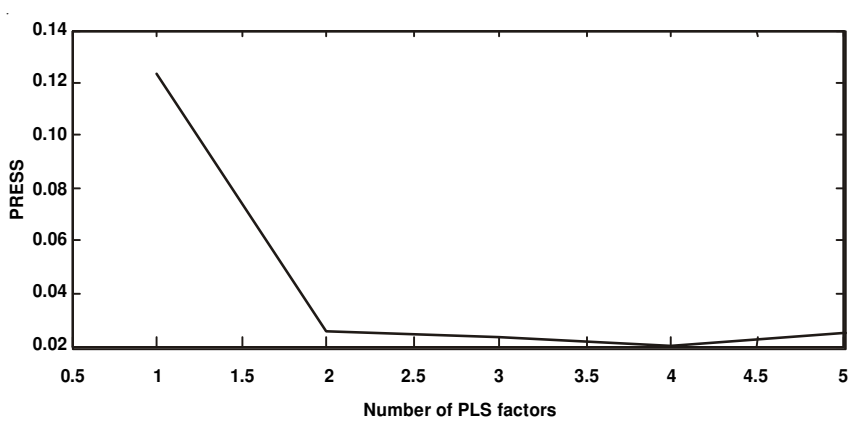

Fig. 9. Plot of PRESS of cross-validation for Al-xylenol orange as a function of the number of factors (h) obtained by PLS-1 calibration

where $\mathrm{n}$ is the number of samples in prediction set (6 in this study).

The root mean squares difference (RMSD) can give an indication of the average error of each analyte in the analysis. RMSD can be calculated in prediction samples by the following equation $^{13}$.

$$
\operatorname{RMSD}=\frac{1}{\sqrt{\mathrm{n}}} \sum_{\mathrm{i}=1}^{\mathrm{n}}\left(\mathrm{C}_{\mathrm{i} \text {, pred }}-\mathrm{C}_{\mathrm{i}, \text { act }}\right)^{2}
$$

SEC $(\mathrm{P})$, the standard error of calibration or prediction, whatever the case, was evaluated by ${ }^{14}$.

$$
\operatorname{SEC}(p)=\sqrt{\frac{\sum_{i=1}^{n}\left(C_{i, \text { pred }}-C_{i, \text { act }}\right)^{2}}{n-1}}
$$

The square of the correlation coefficient $\left(r^{2}\right)$, which reflects the goodness of fit of all data to a line can be obtained from the following equation ${ }^{13,15}$.

$$
r^{2}=1-\left(\frac{\sum_{i=1}^{n}\left(C_{i, p r e d}-C_{i, a c t}\right)^{2}}{\sum_{i=1}^{n}\left(C_{i, a c t}-\bar{C}\right)^{2}}\right)
$$

$\overline{\mathrm{C}}$ is the average analyte concentration in the prediction samples. The calibration parameters obtained from the internal validation (i.e., validation for the calibration set) are presented in Table-3. Table-3 also shows the figures of merit for the proposed method.

TABLE-3

INTERNAL CALIBRATION RESULTS, STATISTICAL PARAMETERS AND THE FIGURES OF MERIT FOR THE PROPOSED PLS-1 METHOD

\begin{tabular}{lc}
\hline Calibration parameter & Al-Xylenol orange \\
\hline Spectral region $(\mathrm{nm})$ & $510-589$ \\
Number of factors $(\mathrm{h})$ & 2 \\
PRESS $\left(\mathrm{mg}^{2} \mathrm{~L}^{-2}\right)$ & 0.006225 \\
RMSD $\left(\mathrm{mg} \mathrm{L}^{-1}\right)$ & 0.0013357 \\
REP $(\%)$ & $4.45 \%$ \\
SEC $(\mathrm{p})$ & 0.0256 \\
$\mathrm{R}^{2}$ & 0.9981 \\
\hline
\end{tabular}

The perfect spectral region for Al-xylenol orange was extended from 510-589 $\mathrm{nm}$. High prediction ability of PLS-1 method for Al-xylenol orange in calibration samples as indicated from $\mathrm{R}^{2}$ and $\mathrm{REP} \%$ values.

The optimized PLS-1 calibration method proposed for aluminium was used to estimate their concentrations in synthetic solutions (Table-2, prediction set). The mean recovery percentages, RSD, SEP and REP \% obtained for prediction set were presented in Table-4. The results were satisfactory indicating the successful application of the proposed method for determination of aluminium in solutions. Fig. 10 shows the plot of predicted concentration versus actual concentration for prediction set.

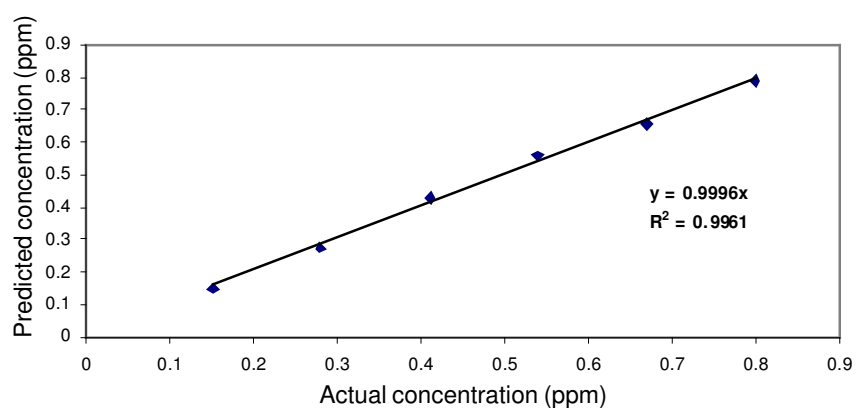

Fig. 10. Plot of predicted concentration versus actual concentration obtained with pls method

TABLE-4

STATISTICAL PARAMETERS ESTIMATED DURING THE EXTERNAL VALIDATION OF THE PLS-1 CALIBRATION METHOD PROPOSED FOR Al-XYLENOL ORANGE

\begin{tabular}{cccc}
\hline $\begin{array}{c}\text { Prediction } \\
\text { solution }\end{array}$ & $\begin{array}{c}\text { Al Added mg/L } \\
\text { (actual conc.) }\end{array}$ & $\begin{array}{c}\text { Al founded mg/L } \\
\text { (predicted conc.) }\end{array}$ & $\begin{array}{c}\text { Recovery } \\
(\%)\end{array}$ \\
\hline 1 & 0.1512 & 0.1523 & 100.7 \\
2 & 0.2808 & 0.2747 & 97.8 \\
3 & 0.4104 & 0.4303 & 104.9 \\
4 & 0.54 & 0.5589 & 103.5 \\
5 & 0.6696 & 0.6572 & 98.1 \\
6 & 0.7992 & 0.7876 & 98.5 \\
\hline
\end{tabular}

Statistical analysis: Average recovery $\pm \operatorname{RSD}(n=6) 100.58 \pm 2.99$. $\operatorname{SEC}(p)=0.0148$. REP $(\%)=2.58 \%$.

Effect of diverse cations: In order to test the effect of diverse cations upon the aluminium determination, absorption measurements were made for the solutions containing 0.648 $\mathrm{mg} / \mathrm{L}$ of $\mathrm{Al}$ and different concentration of diverse cations. The tolerated limits were taken as the concentrations causing changes no greater than $5 \%$ in the measured concentration of analytes. As can be seen from Table-5, among the salts examined, $\mathrm{Fe}^{3+}$ interfere due to the higher formation constant of the metal ion-xylenol orange complexe compared to other metal ionxylenol orange complexes in acidic media.

\begin{tabular}{cccc}
\multicolumn{4}{c}{ TABLE-5 } \\
\multicolumn{4}{c}{ EFFECT OF DIVERS IONS ON THE DETERMINATION } \\
OF 0.648 mg/L of ALUMINIUM \\
\hline Species & Tolerance limit (mg/L) & Species & Tolerance limit (mg/L) \\
\hline $\mathrm{Zn}^{2+}$ & 7.85 & $\mathrm{Ni}^{2+}$ & 4.69 \\
$\mathrm{Cd}^{2+}$ & 224.82 & $\mathrm{Mn}^{2+}$ & 439.52 \\
$\mathrm{~Pb}^{2+}$ & 4.144 & $\mathrm{Hg}^{2+}$ & 240.7 \\
$\mathrm{Fe}^{3+}$ & 0.0448 & $\mathrm{Co}^{2+}$ & 5.89 \\
$\mathrm{Cu}^{2+}$ & 5.12 & - & - \\
\hline
\end{tabular}




\section{Determination of aluminium in real samples}

Water samples: In order to test applicability of the proposed method for drinking water analysis, the aluminium content of three water samples under the optimum conditions were measured by using calibration model. water samples were prepared by applying Jar Test on turbid waters from Qomroud river in Qom city, using aluminium sulphate as a coagulant. The concentration levels of added $\mathrm{Al}$ were selected to be within the linear range obtained from the univariate studies. A good agreement between spiked water and real samples was seen. The recovery values obtained in the analysis of the spectral data of the samples were summarized in Table- 6 . The recoveries obtained were satisfactory in all the samples analyzed where the values of RSD were less than $10 \%$. The prediction power of PLS-1 can be considered acceptable taking into account the complexity of the sample being analyzed. The good agreement between the obtained results using PLS-1 and the spiked values is an indication of the effectiveness of the proposed method for determination of $\mathrm{Al}$ in real samples. In fact, other substances that present in natural water samples which where not considered in the calibration model, e.g., $\mathrm{Cl}^{-}, \mathrm{SO}_{4}{ }^{2-}, \mathrm{NO}_{3}{ }^{-}$ etc., did not strongly interfere with $\mathrm{Al}$ analysis.

\begin{tabular}{|c|c|c|c|c|}
\hline \multicolumn{5}{|c|}{$\begin{array}{c}\text { TABLE-6 } \\
\text { DETERMINATION OF ALUMINIUM IN DIFFERENT WATER } \\
\text { SAMPLE USING PROPOSED PROCEDURES }\end{array}$} \\
\hline $\begin{array}{c}\text { Water } \\
\text { sample* }\end{array}$ & $\begin{array}{l}\text { Al found } \\
(\mathrm{mg} / \mathrm{L})\end{array}$ & $\begin{array}{l}\text { Al added } \\
(\mathrm{mg} / \mathrm{L})\end{array}$ & $\begin{array}{l}\mathrm{Al} \text { (spiked + sample } \\
\text { water found }(\mathrm{mg} / \mathrm{L})\end{array}$ & $\begin{array}{c}\text { Recovery } \\
(\%)\end{array}$ \\
\hline Water 1 & 0.551 & 0.108 & 0.656 & 97.22 \\
\hline Water 2 & 0.671 & 0.108 & 0.780 & 100.13 \\
\hline Water 3 & 0.590 & 0.108 & 0.696 & 98.15 \\
\hline \multicolumn{5}{|c|}{$\begin{array}{l}\left.\text { *The employed tap water contains (in } \mathrm{mg} \mathrm{L}^{-1}\right):\left[\mathrm{Cl}^{-}\right]=130,\left[\mathrm{SO}_{4}{ }^{2-}\right]= \\
75 \text {, total hardness }\left(\text { as } \mathrm{CaCO}_{3}\right)=680 \mathrm{mg} \text { and alkalinity }\left(\text { as } \mathrm{CaCO}_{3}\right)= \\
225 \mathrm{mg} \mathrm{L}^{-1} \text {. }\end{array}$} \\
\hline
\end{tabular}

Industrial samples: The accuracy and applicability of the proposed method was also evaluated by its application to various industrial samples. Aluminium gel tablets and a bauxite and a bentonit samples were examined for aluminium content.

Aluminium gel tablets: An aluminium gel tablet was converted to a fine powder by a Mortar and then it was dissolved in $40 \mathrm{~mL}$ of $0.5 \mathrm{M} \mathrm{HCl}$ by heating on a hot plate. The solution was cooled, filtered, adjusted the $\mathrm{pH}$ to 3 and then diluted to $100 \mathrm{~mL}$ with distilled water in a calibrated volumetric flask. An aliquot of this sample was analyzed by the general procedure.

Bentonite and bauxite sample: A $1 \mathrm{~g}$ sample for bentonit and $0.25 \mathrm{~g}$ for bauxite was dissolved in $40 \mathrm{~mL}$ of $0.5 \mathrm{M} \mathrm{HCl}$ by heating on a hot plate; the solution was cooled and adjusted its $\mathrm{pH}$ in 12 by adding $6 \mathrm{M} \mathrm{NaOH}$ solution(to remove $\mathrm{Fe}^{3+}$ ) and then filtered, adjusted the $\mathrm{pH}$ in 3 by adding $\mathrm{HCl}$ and then diluted to $100 \mathrm{~mL}$ with distilled water in a calibrated volumetric flask. An aliquot of this sample were analyzed by the general procedure. The results are summarized in Table- 7 .

\begin{tabular}{lcc}
\hline & \multicolumn{2}{c}{ TABLE-7 } \\
& $\begin{array}{c}\text { DETERMINATION OF Al IN SOME } \\
\text { INDUSTRIAL SAMPLE }(\mathrm{n}=3)\end{array}$ \\
\hline \multicolumn{1}{c}{ Sample } & $\mathrm{Al}$ found by & $\mathrm{Al}$ found by A.A \\
& proposed method & $\mathrm{Al}_{2} \mathrm{O}_{3} 51.71 \%$ \\
\hline Bauxite sample & $\mathrm{Al}_{2} \mathrm{O}_{3} 51.23 \%$ & $\mathrm{Al}_{2} \mathrm{O}_{3} 14.3 \%$ \\
Bentonit sample & $\mathrm{Al}_{2} \mathrm{O}_{3} 13.92 \%$ & $\mathrm{Al}(\mathrm{OH})_{3} 240$ \\
Aluminium gel tablet & $\mathrm{Al}(\mathrm{OH})_{3} 244.4$ & $\mathrm{mg} /$ tablet \\
\hline
\end{tabular}

\section{Conclusion}

A new method for the spectrophotometric determination of aluminium using xylenol orange and partial least squares method is proposed. The results demonstrate that xylenol orange is an effective metallochromic indicator for determination of trace amounts of $\mathrm{Al}(\mathrm{III})$ ion as its complex with xylenol orange only iron can be a serious interfering ion that can be remove completely by alkalizing the solution and filtering its precipitate. The proposed determination method gives a good RSD values. The method can be successfully applied to the determination of aluminium in water samples and some minerals and aluminium gel tablets.

\section{REFERENCES}

1. M.Otomo, Bull. Chem. Soc. Japan, 36, 809 (1963).

2. M.B. Gholivand, F. Bamdad and J. Ghasemi, Talanta, 46, 875 (1998).

3. A. Dodson and V.J. Jenning, Talanta, 19, 801 (1972).

4. T. Madrakian, A. Afkhami, M. Borazjani and M. Bahram, Spectrochim. Acta A, 61, 2988 (2005).

5. A.C. Edvards and M.S. Creaser, Talanta, 30, 702 (1983).

6. A.R. Coscione and J.C. Andrade, Anal. Chim. Acta, 423, 31 (2000).

7. J. Ghasemi, A. Niazi and M. Noroozi, J. Sci. Islamic Republic Iran, 17, 35 (2006).

8. R.G. Brereton, Applied Chemometrics for Scientists, John Wiley \& Sons, Ch. 6 (2007).

9. D.L. Massart, B.G.M. Vandeginste, S.N. Deming, Y. Michotte and L. Kaufman, Chemometrics: A Textbook. Elsevier, Amsterdam (1988).

10. J. Ghasemi, A. Niazi and R. Leardi, Talanta, 59, 311 (2003).

11. D. Haaland and E. Thomas, Anal. Chem., 60, 1193 (1988).

12. B. Hemmateenejad, A. Abbspour and H. Maghami, Anal. Chim. Acta, 29. 575 (2006).

13. A. Abbaspour and M. Najafi, Talanta, 60, 1079 (2003).

14. P. López-de-Alba and L. López-Martínez, J. Braz. Chem. Soc., 17, 715 (2006).

15. B. Hemmateenejad, M. Akhond and J. Tashkhourian, J. Anal. Chem., 61, 804 (2006). 